\title{
State of the art of where we are at using stem cells for stress urinary incontinence
}

\author{
Furuta A, Jankowski RJ, Honda M, Pruchnic R, Yoshimura N, Chancellor MB
}

Department of Urology, University of Pittsburgh School of Medicine, Pennsylvania, USA

Neurourol Urodyn. 2007; 26: 966-71

\begin{abstract}
Aims: This review aims to discuss: 1) the neurophysiology, highlighting the importance of the middle urethra, and treatment of stress urinary incontinence (SUI); 2) current injectable cell sources for minimally-invasive treatment; and 3) the potential of muscle-derived stem cells (MDSCs) for the delivery of neurotrophic factors.

Methods: APUB-MED search was conducted using combinations of heading terms: urinary incontinence, urethral sphincter, stem cells, muscle, adipose, neurotrophins. In addition, we will update the recent work from our laboratory.

Results: In anatomical and functional studies of human and animal urethra, the middle urethra containing rhabdosphincter, is critical for maintaining continence. Cell-based therapies are most often associated with the use of autologous multipotent stem cells, such as the bone marrow stromal cells. However, harvesting bone marrow stromal stem cells is difficult, painful, and may yield low numbers of stem cells upon processing. In contrast, alternative autologous adult stem cells such as MDSCs and adipose-derived stem cells can be easily obtained in large quantities and with minimal discomfort. Not all cellular therapies are the same, as demonstrated by the differences in safety and efficacy from muscle-sourced MDSCs versus myoblasts versus fibroblasts. Conclusions: Transplanted stem cells may have the ability to undergo self-renewal and multipotent differentiation, leading to sphincter regeneration. In addition, such cells may release, or be engineered to release, neurotrophins with subsequent paracrine recruitment of endogenous host cells to concomitantly promote a regenerative response of nerve-integrated muscle. The dawn of a new paradigm in the treatment of SUI may be near.
\end{abstract}

\section{Editorial Comment}

The authors describe the current status of research into using stem cell therapy for stress urinary incontinence. This is an excellent read for those who wish to gaze through the looking glass into the future of urology. The last paragraph of the Introduction section alone is worth reading and looking back upon in one or 
two decades to see if the predictions are fulfilled. Clearly, patient interest will continue to drive us away from surgery and into minimally invasive therapies to restore functionality to diseased areas of the urologic system. One does not have to wait a decade to already notice this desire (1). The section on neurophysiology is clear and distinct as is the discussion on stem cell therapy and the reasoning of using muscle-derived stem cells.

\section{Reference}

1. Petrou SP, Lisson SW, Crook JE, Lightner DJ: An exploration into patient preference for injectable therapy over surgery in the treatment of female urinary incontinence. Int Braz J Urol. 2006; 32: 578-82.

Dr. Steven P. Petrou

Associate Professor of Urology

Chief of Surgery, St. Luke's Hospital

Associate Dean, Mayo School of Graduate Medical Education

Jacksonville, Florida, USA

E-mail: petrou.steven@mayo.edu

\section{Does the tension-free vaginal tape procedure (TVT) affect the voiding function over time? Pressure- flow studies 1 year and 3(1/2) years after TVT}

Sander P, Sørensen F, Lose G

Department of Obstetrics and Gynaecology, Glostrup County Hospital, University of Copenhagen, Glostrup, Denmark

Neurourol Urodyn. 2007; 26: 995-7

Aim: The aim was to evaluate the voiding function over time after the TVT procedure for stress incontinence. Materials and Methods: Thirty-eight women with urodynamic stress urinary incontinence were included in the study. For voiding function assessment the patients were asked if voiding had changed postoperatively, and objectively uroflowmetry, residual urine measurement and pressure-flow were performed preoperatively, 1 year and 3(1/2) years postoperatively.

Results: At 1/3(1/2) years follow-up 87\%/69\% were subjectively cured and 13\%/26\% improved, respectively. The objective cure rate was $89 \% / 74 \%$. Subjectively $77 \% / 63 \%$ of the patients felt an altered voiding function towards more difficult voiding one and 3(1/2) years after surgery, respectively. Objectively all the uroflowmetry variables deteriorated and residual urine volume increased over time although the changes were not statistically significant between the 1 and 3(1/2) years follow-up. Pressure-flow variables were essentially unchanged. Conclusion: The changes in voiding function after a TVT do not reverse over time. This may imply a potential risk of development of clinically important impaired emptying function.

\section{Editorial Comment}

The authors of this paper reviewed both subjective as well as objective data in evaluating voiding habits and bladder function 1 year and 3(1/2) years after placement of a TVT. The researchers found that there was a steady deterioration in uroflow measures as well as an increase in residual urine between the initial and longterm follow-up. Urodynamic criteria were essentially unchanged.

This study is quite interesting in that it explores the question of what happens long-term to voiding function after a no-tension technique anti-incontinence operation. Those patients will often view a successful operation as imperfect based on voiding habits has previously been reported (1) and is well evidenced here by comparing the patient perceptions with the pad and leakage episodes reported in the manuscript table. The noted worsening of uroflow measures and the increase in post void residuals from the 1 year mark to 3(1/2) years mark 
raises the concern of what happens to the younger patient who has an anti-incontinence procedure at the time of her pelvic prolapse surgery in her forties: is she doomed to a life of voiding dysfunction and possible pharmacological therapy from age 60 onwards? This should be food for thought for the clinician who adds a sling as a prophylactic step to the prolapse surgery planned.

\section{Reference}

1. Haab F, Trockman BA, Zimmern PE, Leach GE: Results of pubovaginal sling for the treatment of intrinsic sphincter deficiency determined by questionnaire analysis. J Urol. 1997; 158: 1738-41.

Dr. Steven P. Petrou

Associate Professor of Urology

Chief of Surgery, St. Luke's Hospital

Associate Dean, Mayo School of Graduate Medical Education

Jacksonville, Florida, USA

E-mail: petrou.steven@mayo.edu 